The authors dedicate this article to Jim Matio. Every community Jim lived in benefited from his humor, compassion, and love for others.

\section{Authors JOHN R. GALLAGHER} Associate Professor, Indiana University School of Social Work

\section{ANNE NORDBERG}

Associate Professor, University of Texas at Arlington School of Social Work

\section{RAYCHEL MINASIAN}

Addictions Therapist, Oaklawn Psychiatric Center

\section{SYDNEY SZYMANOWSKI}

Graduate Research Assistant (GRA), Indiana University School of Social Work

\section{JESSE CARLTON}

Chief Probation Officer, St. Joseph County, IN Probation

\section{KRISTIN FEE}

Drug Court Coordinator, St. Joseph County, IN Drug Court

\section{JANE WOODWARD MILLER} Drug Court Judge, St. Joseph County, IN Drug Court

\section{JOHN HORSLEY}

Vice President of Adult Services, Oaklawn Psychiatric Center

\section{TARA PAIANO}

Drug Court Coordinator, Elkhart County, IN Drug Court

\title{
Community-engaged Research (CER) as the Avenue to Promoting Well-being and Recovery in Drug Court
}

JOHN R. GALLAGHER, ANNE NORDBERG, RAYCHEL MINASIAN, SYDNEY SZYMANOWSKI, JESSE CARLTON, KRISTIN FEE, JANE WOODWARD MILLER, JOHN HORSLEY AND TARA PAIANO

\section{ABSTRACT}

Drug courts are an alternative to incarceration for individuals who have substance use disorders and have been arrested for drug-related crimes (e.g. possession of a controlled substance). The first drug court began in 1989 in Florida and it is estimated that there are over 3,000 drug courts now operating throughout the United States. This community-engaged research (CER) evaluated the St. Joseph County (Indiana) drug court by identifying who was most likely to graduate, who was most likely to recidivate, and whether drug court or probation was more effective at reducing criminal recidivism. Furthermore, although drug courts are found in many communities, research rarely describes the process used to develop and implement CER. Therefore, this article also highlights the collaborative process used in this drug court evaluation. The findings from this study suggest that the St. Joseph County (Indiana) drug court is an effective program at reducing criminal recidivism and a valuable resource for individuals who have substance use disorders, the community, and other stakeholders. Drug court participants were less likely to recidivate than probationers, and a lower recidivism rate clearly equates to many benefits to the community. The article concludes with community-based implica- 
tions, such as starting recovery support groups that are welcoming to individuals who receive medication-assisted treatment (MAT), marketing drug court to racial and ethnic minorities to increase their representation in the program, and disseminating research findings throughout the community via local news stories, podcasts, and public lectures.

Keywords: community-engaged research (CER), criminal justice, drug court, recidivism, social work, substance use disorder

\section{INTRODUCTION}

In the late 1980s, criminal justice stakeholders in Miami, Florida decided to address an ongoing problem within the justice system. They had noticed that people charged and convicted of minor drug offenses, such as possession, often reappeared before the courts with the same charges (Wexler \& Winick, 1996). This so-called revolving door was backlogging the courts and punishment seemed ineffective to deter future criminal justice involvement. It cost all involved and the community time, effort, and money with no positive outcomes. These stakeholders operationalized therapeutic jurisprudence or the idea that criminal courts could be part of therapeutic solutions, particularly for men and women who had substance use disorders (Schneider, Bloom, \& Hereema, 2007). For people caught in the dragnet of the war on drugs, treatment for substance use disorders may be a more effective option than incarceration. As a result, they implemented the first drug court in 1989 (Nolan, 2001) by diverting people away from the traditional, punitive approach to justice into this first drug court that placed the court, the judge, and criminal justice professionals amidst a drug rehabilitation program (Schneider et al., 2007; Slinger \& Roesch, 2010; Wexler \& Winick, 1996). The court differed dramatically in several ways. For instance, the adversarial nature of the traditional criminal justice process was suspended with prosecutors and defense attorneys collaborating for the best interests of participants and criminal justice workers, especially the judge, became part of the therapeutic paradigm.

Drug court was a choice for participants and in accepting the diversion, they agreed to plead guilty, remain drug free, which was measured through self-report and random and frequent drug tests, follow treatment recommendations, and report to drug court for supervision (Wexler \& Winick, 1996). Goldkamp (1994) conducted an evaluation of this first drug court and found promising outcomes. Specifically, recidivism rates among drug court graduates was assessed at $32 \%$ compared to 48 to $55 \%$ among comparison groups. Since then, many other studies have confirmed Goldkamp's positive findings, such as a large-scale governmental study (U.S. Government Accountability Office, 2005) and meta-analyses and systematic reviews (Aos, Miller, \& Drake, 2006; Lowenkamp, Holsinger, \& Latessa, 2005; Mitchell, Wilson, Eggers, \& MacKenzie, 2012; Wilson, Mitchell, \& MacKenzie, 2006). Notwithstanding the contradictory results of a few studies (Brown, 2010; Miethe, Lu, \& Reese, 2000), the drug court model was deemed so successful that it has been adapted for other populations, such as people with mental illnesses (Schneider et al., 2007) Additionally, drug courts and other treatment courts (e.g. mental health courts, veterans courts, family treatment courts) have been replicated over 3,000 times and are found in all 50 states, as well as other countries, such as Canada, Ireland, United Kingdom, and Australia, to name a few (National Association of Drug Court Professionals, 2019).

\section{COMMUNITY-ENGAGED RESEARCH (CER)}

Drug court stakeholders collaborated with the researchers on all aspects of this study. The drug court judge, chief probation officer, and drug court

Note: This research was funded by a grant from the Indiana University School of Social Work, Center for Social Health and Well-Being. 
coordinator were the main stakeholders involved in the process, but feedback and insight was welcomed from the entire drug court team. Treatment providers and prosecuting and defense attorneys, for example, also helped with the research design. Drug court is a criminal justice, community-based program; therefore, it was important that the research design and the findings be understandable to lay persons, those without academic or statistical backgrounds. With that in mind, the drug court and research teams identified the best methodology to reach laypersons. For instance, it was decided to use statistics that produce percentages, which are easily understandable to laypersons.

That is just one example of the in-depth collaboration between the drug court and research teams. The collaboration also included developing the research questions for this study, interpreting the findings and exploring the implications of the findings, disseminating the knowledge gained from this study to drug court participants, the community, and others, and working on manuscripts, such as this one, to reach international, multidisciplinary audiences. The purpose of this CER was to answer the following three research questions. First, which drug court participants are most likely to graduate? Second, which drug court participants are most likely to recidivate? Third, is drug court or probation more effective at reducing criminal recidivism?

\section{METHODOLOGY}

The data collection for this study did not involve human subjects; therefore, this research was not subject to Institutional Review Board (IRB) regulations. A graduate research assistant (GRA) collaborated with the chief of probation and drug court coordinator to collect the necessary data from participant's electronic charts.

\section{GRADUATION}

To determine which drug court participants were most likely to graduate, data were collected on all participants $(n=178)$ who either graduated or were terminated from drug court from 2015 to 2018. The outcome variable was graduation. There were eight predictor variables. ${ }^{1}$ The predictor variables were gender, ethnicity, education at time of admission into drug court, employment or student at time of admission into drug court, drug of choice, violation within first 30 days of drug court, mental health, and time between arrest and admission.

\section{CRIMINAL RECIDIVISM}

To determine which drug court participants were most likely to recidivate, data were collected on all participants $(n=178)$ who either graduated or were terminated from drug court from 2015 to 2018. There were nine predictor variables and one outcome variable. ${ }^{2}$ The outcome variable was re-

\footnotetext{
${ }^{1}$ A predictor variable explains changes in the outcome variable. The outcome variable was graduation $(0=$ terminated, $1=$ graduated $)$. The predictor variables were as follows: gender $(0=$ female, $1=$ male), ethnicity $(0=$ non-white, $1=$ white $)$, education $(0=\operatorname{did}$ not have a high school diploma or equivalent at time of admission into drug court, 1 = had a high school diploma or equivalent at time of admission into drug court), employment or student $(0=$ not employed or a student at time of admission into drug court, $1=$ employed or a student at time of admission into drug court), drug of choice $(0=$ heroin and other opioids, $1=$ non-opioids), first 30 days $(0=$ had a violation within the first 30 days of drug court, $1=$ did not have a violation within the first 30 days of drug court), mental health $(0=$ depressive disorder, 1 = no depressive disorder), and time between arrest and admission ( $0=$ was admitted/plead into drug court 91 days or more following arrest, 1 = was admitted/plead into drug court 90 days or less following arrest).

${ }^{2}$ The outcome variable was $(0=$ did not recidivate, $1=$ recidivated $)$. The predictor variables were as follows: gender $(0=$ female, $1=$ male), ethnicity $(0=$ non-white, $1=$ white $)$, education $(0=$ did not have a high school diploma or equivalent at time of admission into drug court, $1=$ had a high school diploma or equivalent at time of admission into drug court), employment or student $(0=$ not employed or a student at time of admission into drug court, $1=$ employed or a student at time of admission into drug court), drug of choice ( $0=$ heroin and other opioids, $1=$ non-opioids), first 30 days $(0=$ had a violation within the first 30 days of drug court, $1=$ did not have a violation within the first 30 days of drug court), mental health $(0=$ depressive disorder, $1=$ no depressive disorder), time between arrest and admission $(0=$ was admitted/plead into drug court 91 days or more following arrest, $1=$ was admitted/plead into drug court 90 days or less following arrest), and outcome ( 0 = terminated, 1 = graduated $)$.
} 
cidivism. The predictor variables were as follows: gender, ethnicity, education at time of admission into drug court, employment or student at time of admission into drug court, drug of choice, violation within first 30 days of drug court, mental health, time between arrest and admission, and graduation.

Additionally, to compare the recidivism rates between drug court participants and probationers, data were collected on probationers $(n=186)$ who had an outcome revoked or completed from 2015 to 2018. Probationers were matched to the drug court sample by arrest/offense type, meaning they had an arrest/offense that was eligible for drug court but they did probation instead. Probationers and drug court participants were also matched by their Indiana Risk Assessment System (IRAS) scores; both groups had a start score of 21 . The IRAS score indicates an individual's risk of recidivating. The score also assists criminal justice professionals in developing individualized treatment plans and interventions to increase individuals' protective factors (e.g. gaining and sustaining employment, abstaining from illicit drug use, having stable housing). Recidivism data were collected through Odyssey, an electronic system for filing criminal cases in St. Joseph County (Indiana). Recidivism was defined as any new local (St. Joseph County, Indiana) arrest for a felony or misdemeanor offense that resulted in charges being filed during drug court/probation and up to 36 months post drug court/probation discharge. The definition of recidivism was provided by the drug court and approved by the Indiana Office of Court Services, Problem-Solving Courts Committee, a division of the state government that certifies Indiana problem-solving courts. The recidivism data were collected in 2019.

\section{FINDINGS}

The findings are presented in reference to the three research questions. Starting in 2013, the drug court for this study completed a program evaluation once every three years; therefore, the current findings are compared and contrasted with the 2013 and 2016 program evaluations (Gallagher, 2013; Gallagher, Ivory, Carlton, \& Woodward Miller, 2014; Gallagher, Wahler, \& Lefebvre, 2016; Gallagher et al., 2018).

\section{Which drug court participants are most likely to graduate?}

Statistics were used to determine if significant differences existed in graduation outcomes. The analyses revealed that four predictor variables were significantly associated with graduating drug court. First, participants who had a high school diploma or equivalent at the time they were admitted to drug court were more likely to graduate (60\%) than participants who did not have a high school diploma or equivalent at admission (42\%) ${ }^{3}$. Second, participants who did not have a violation within the first 30 days of drug court were more likely to graduate (73\%) than participants who had a violation during this timeframe $(22 \%)^{4}$. The violations included in the analysis were dilute drug screens, positive drug screens indicating new drug use, missed treatment or court appointments, and new arrest. Third, non-White participants were more likely to graduate (62\%) than White participants $(47 \%)^{5}$. Fourth, participants who were admitted/plead to drug court 91 days or more following their arrest were more likely to graduate (61\%) than participants who were admitted/plead to drug court 90 days or less following their arrest $(46 \%)^{6}$.

\footnotetext{
${ }^{3}\left(X^{2}=5.12, p<0.05\right)$

${ }^{4}\left(X^{2}=46.09, p<0.01\right)$
}

${ }^{5}\left(X^{2}=2.76 p<0.10\right)$

${ }^{6}\left(X^{2}=2.93, p<0.10\right)$ 


\section{FIGURE 1}

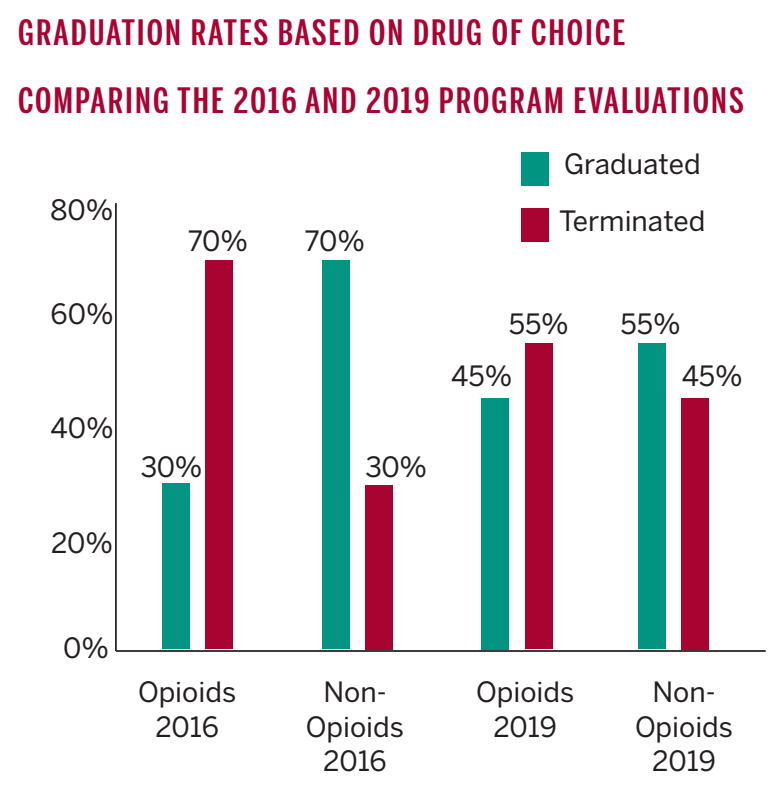

Other notable findings were that women and men graduated drug court at relatively equal rates and there was a $10 \%$ difference in graduation rates between participants who identified heroin or other opioids as their drug of choice versus those who identified non-opioids as their drug of choice. Specifically, $55 \%$ of the women and $47 \%$ of the men graduated drug court ${ }^{7}$. In regard to drug of choice, $45 \%$ of the participants who identified heroin or other opioids as their drug of choice graduated, compared to a $55 \%$ graduation rate for participants who identified non- opioids as their drug of choice ${ }^{8}$. As noted in Figure 1, in the 2016 program evaluation, only $30 \%$ of participants who identified heroin or other opioids as their drug of choice graduated drug court; therefore, the current graduation rate of $45 \%$ for this population is a promising finding. Also, 91 drug court participants (51\%) identified heroin or other opioid as their drug of choice and 87 participants (49\%) identified non-opioids as their drug of choice. For
FIGURE 2

\section{DRUG COURT GRADUATION RATES}

COMPARING THE 2013, 2016, AND 2019 PROGRAM EVALUATIONS

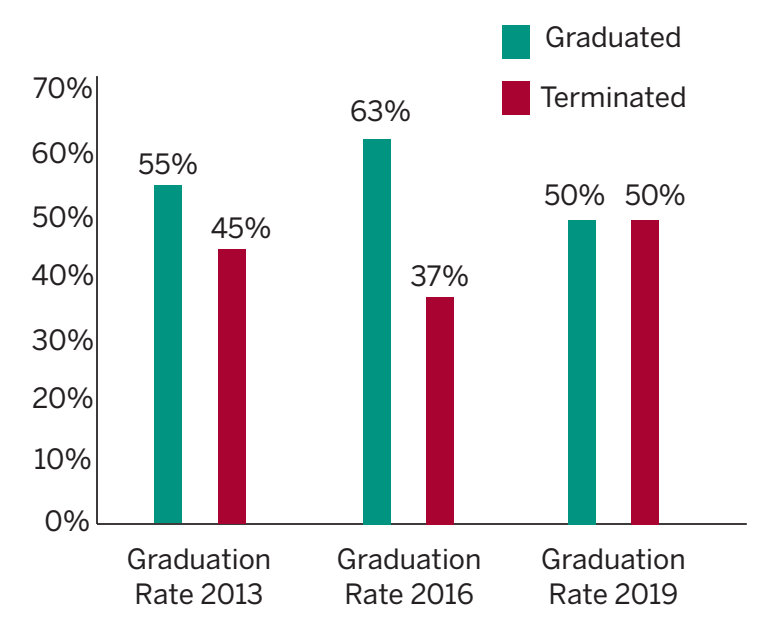

participants who identified heroin or other opioids as their drug of choice ( $\mathrm{n}=91)$, about $50 \%$ $(n=45)$ received a medication-assisted treatment (MAT) while in drug court. Of those who received a MAT, 38 were prescribed naltrexone (e.g. Vivitrol) and seven were prescribed buprenorphine (e.g. Suboxone). When comparing those who received a MAT $(n=45)$ versus those who did not $(n=46)$, the graduation rates were relatively the same. Specifically, $46 \%$ of those who did not receive a MAT graduated drug court, compared to a $44 \%$ graduation rate for those who received a MAT $^{9}$.

Next, Figure 2 compares drug court graduation rates from the 2013 and 2016 program evaluations to this 2019 study. As noted in the figure, from 2013 to 2016, the graduation rate increased by eight percent. However, from 2016 to 2019, there was a $13 \%$ decrease in graduation rate. The decrease in graduation rate does not require

\footnotetext{
${ }^{7}\left(X^{2}=0.88, p=0.35\right)$

${ }^{8}\left(X^{2}=1.82, p=0.18\right)$

${ }^{9}\left(X^{2}=0.01, p=0.91\right)$
} 
urgent attention, but the rate should be monitored on a yearly basis to assess the trend over time. Nationally, the majority of drug courts have a graduation rate between $50 \%$ and $75 \%$, so the St. Joseph County (Indiana) drug court is in that range (Marlowe, Hardin, \& Fox, 2016). Also, it is important to note that a lower graduation rate does not mean a particular drug court is less effective. Some drug courts, for instance, with lower graduation rates may accept participants with high criminogenic risk factors (e.g. criminal histories, severe substance use disorders, unemployment, etc.) and it is expected that these programs will have a lower graduation rate than drug courts that only accept low risk participants. Furthermore, the opioid epidemic has had devastating consequences on individuals, families, and communities and social service and healthcare systems have often responded to the epidemic retroactively, at no fault to them, the systems simply could not predict the magnitude of the problem. Presumably, drug courts may have also shown a similar pattern where many programs were unprepared for the opioid epidemic and logically this would have a negative impact on graduate rates.

\section{Which drug court participants are most likely to recidivate?}

Statistics were used to determine if significant differences existed in recidivism outcomes. The analyses revealed that two variables were significantly associated with recidivism. First, and not surprisingly, participants who were terminated from drug court were more likely to recidivate (52\%) than graduates $(21 \%)^{10}$. Second, non-White participants were more likely to recidivate (49\%) than White participants $(33 \%)^{11}$. This finding is surprising, considering non-White participants were more likely to graduate than White participants (62\% and 47\%, respectively) and graduating drug court seems to decrease the risk of recidivism. Perhaps non-White participants experience more post-drug court risk factors (e.g. peers who use drugs, limited recovery support system, poverty, etc.) than White participants that negatively impact their ability to sustain their recovery, but only future research will help determine whether this is true or not. In the 2016 program evaluation, $53 \%$ of non-White participants recidivated; therefore, there has been a four percent decrease in the recidivism rate for this population.

Other notable findings were that women and men recidivated at similar rates and the recidivism rate among the drug of choice variable was relatively equal. Specifically, $31 \%$ of the women and $40 \%$ of the men recidivated ${ }^{12}$. In regard to drug of choice, $34 \%$ of the participants who identified heroin or other opioids as their drug of choice recidivated, compared to a $39 \%$ recidivism rate for participants who identified non-opioids as their drug of choice $^{13}$. As mentioned previously, for the participants who identified heroin or other opioid as their drug of choice $(n=91)$, about $50 \%(n=45)$ received a medication-assisted treatment (MAT) while in drug court. When comparing those who received a MAT $(n=45)$ versus those who did not $(n=46)$, the recidivism rates were relatively the same. Specifically, 33\% of those who did not receive a MAT recidivated, compared to a $36 \%$ recidivism rate for those who received a MAT ${ }^{14}$. Additionally, for the entire drug court sample, their Indiana Risk Assessment System (IRAS) scores decreased from 21 at the start of the program to 17 by the end of the program.

\footnotetext{
${ }^{10}\left(X^{2}=17.67, p<0.01\right)$

${ }^{11}\left(X^{2}=2.97, p<0.10\right)$

${ }^{12}\left(X^{2}=1.20, p=0.27\right)$
}

${ }^{13}\left(X^{2}=0.48, p=0.49\right)$

${ }^{14}\left(X^{2}=0.09, p=0.77\right)$ 
FIGURE 3

DRUG COURT AND PROBATION RECIDIVISM RATES

COMPARING THE 2013, 2016, AND 2019 PROGRAM EVALUATIONS

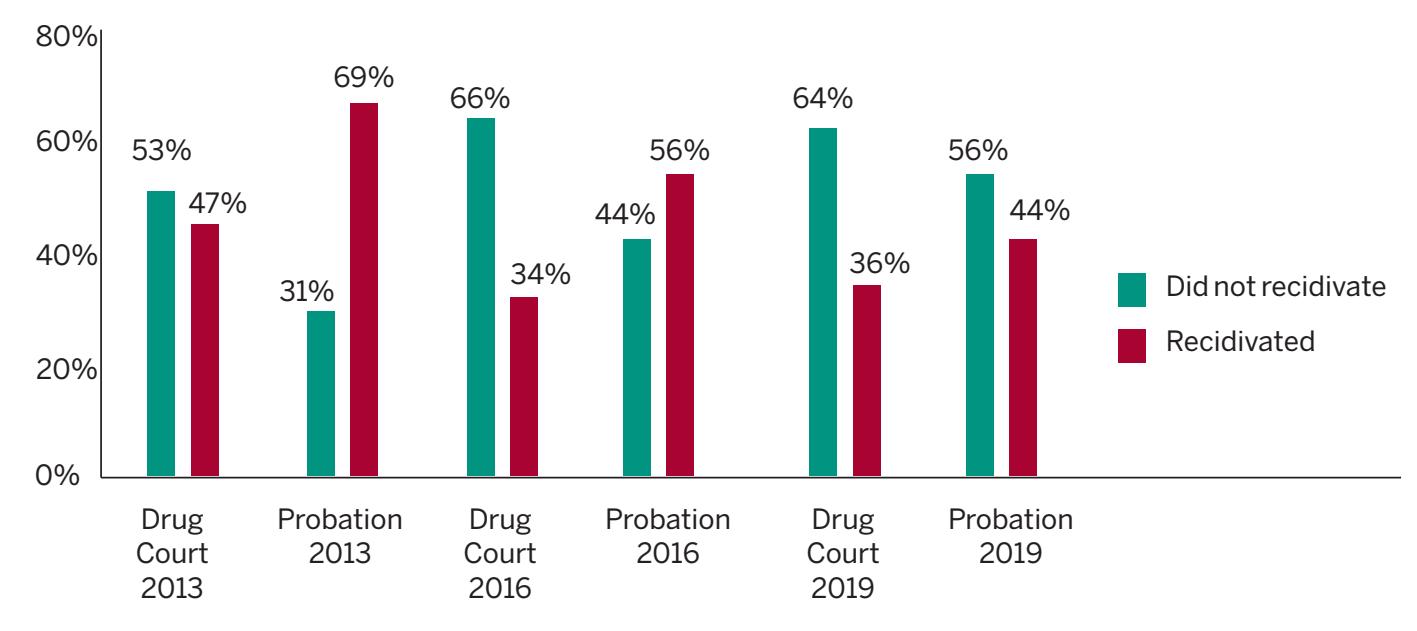

\section{Is drug court or probation more effective at reducing criminal recidivism?}

The recidivism rate of drug court participants was compared to that of probationers. As noted in Figure 3, drug court participants were less likely to recidivate than probationers (36\% and 44\%, respectively). This eight percent difference in recidivism rates highlights the effectiveness of the St. Joseph County (Indiana) drug court. Participants of drug court recidivate less than probationers, and this equates to many benefits to the county, such as cost savings by having to prosecute less criminal cases, presumably less drug use and drug-related crime in the county, and the many benefits that come from recovery (e.g. improved quality of life, higher employment rates, healthier lifestyles, to name a few). It is also important to highlight that, although the graduation rate for the St. Joseph County (Indiana) drug court decreased from 2016 to 2019 (please see Figure 1), the recidivism rates from 2016 to 2019 stayed relatively the same (34\% and 36\%, respectively), suggesting that even those who were terminated from drug court benefited from the pro- gram, in regard to reducing the risk of recidivating. Additionally, when comparing the 2013 findings for drug court to the current findings, there has been an $11 \%$ decrease in recidivism in the past six years. Specifically, in 2013, the recidivism rate was $47 \%$ and in 2019 , the recidivism rate is $36 \%$.

\section{DISCUSSION}

Findings from this CER suggest that the St. Joseph County (Indiana) drug court is an effective program at reducing criminal recidivism and a valuable resource for individuals who have substance use disorders, the community, and other stakeholders. Drug court participants were less likely to recidivate than probationers, and this finding is consistent with meta-analytic reviews of drug courts' impact on recidivism (Mitchell et al., 2012; Shaffer, 2011) and results from evaluations of single drug courts (Brown, 2011). In this study specifically, only $36 \%$ of drug court participants recidivated, whereas the recidivism rate for probationers was $44 \%$. This eight percent difference in recidivism rates highlights the effectiveness of the drug court, and a lower recidivism rate equates to many benefits to St. 
Joseph County (Indiana), such as cost savings by having to prosecute less criminal cases, presumably less drug use and drug-related crime in the county, and the many benefits that come from recovery (e.g. improved quality of life, higher employment rates, healthier lifestyles, to name a few).

\section{Recovery Coaches, Future CER, and the First 30 Days in Drug Court}

Participants who have a violation within the first 30 days of drug court are consistently less likely to graduate than their counterparts who do not have a violation during this timeframe. This finding is true for the 2013 and 2016 program evaluations (Gallagher, 2013, Gallagher et al., 2016) and for this 2019 study, suggesting that the first month of the program is a critical time in determining whether a participant will complete the program or not. The drug court currently has recovery coaches, an intervention they did not have during the 2013 and 2016 program evaluations. As a result, it is recommended that high-risk participants (based on IRAS scores and other assessment tools) be provided with a recovery coach immediately upon admission to the program. Recovery coaches can connect high-risk participants to the community by assisting them in accessing recovery support groups, providing transportation to and from treatment, helping them apply for, gain, and sustain employment, and encourage other protective factors that may decrease the risk of having a violation within the first 30 days of the program. Additionally, future research is needed in this area to assess the specific challenges that some participants face in the first month of the program. It is recommended that for the 2022 program evaluation, qualitative research methods be used, such as focus groups or individual interviews, to learn participants' thoughts, opinions, and experiences related to the first month of drug court. Drug court participants are key stakeholders in CER and they may provide a behind-the-scenes perspective on the program that cannot be captured quantitatively.

\section{MAT and Community-Based Recovery Support Groups}

In light of a national opioid epidemic, it is promising that $45 \%$ of the participants who identified heroin or other opioids as their drug of choice graduated. In comparison, in the 2016 program evaluation, only $30 \%$ of participants who identified heroin or other opioids as their drug of choice graduated (Gallagher et al., 2018). Furthermore, of the drug court participants who identified heroin or other opioid as their drug of choice, about half received a MAT while in the program, most commonly naltrexone (e.g. Vivitrol) followed by buprenorphine (e.g. Suboxone).

Despite evidence that MAT is an effective approach in treating opioid use disorders (National Institute on Drug Abuse, 2016), research has suggested that some drug courts may underutilize or not allow participants to take MAT, sometimes because stakeholders had negative views toward MAT and did not consider MAT to be consistent with their abstinence-based philosophy of treatment (Friedmann et al., 2012; Matusow et al., 2013). The findings from this study, however, highlight that the St. Joseph County (Indiana) drug court is prepared to best treat opioid use disorders, and one of the strategies they have used is collaborating with community partners. For instance, the drug court team received training on MAT in order to accurately and effectively incorporate the intervention into their programming, they invited an addictionologist and medical social worker who specializes in MAT to join the drug court team, they had researchers facilitate focus groups with participants who have opioid use disorders to learn their experiences in the program (Gallagher, Marlowe, \& Minasian, 2019a), and they referred participants to treatment providers who have expertise in treating heroin and other opioids.

It is common for drug courts to encourage, or require, their participants to attend community-based recovery support groups, such as Alcohol- 
ics Anonymous (AA) and Narcotics Anonymous (NA). This community support can be helpful to some, but recent qualitative research has suggested that some NA meetings may not be welcoming to individuals who receive MAT, and even worse, some participants reported being stigmatized and judged for using MAT (Gallagher et al., 2019a). Actually, a recent report from Narcotics Anonymous World Services, Inc. (2016) acknowledged that some NA meetings may be less welcoming to individuals receiving MAT and individuals receiving MAT may not be allowed to fully engage in the NA process. Therefore, drug courts must be selective in deciding which community-based recovery support groups they refer their participants to. If groups that are welcoming of MAT are not available in the local community, then drug courts should collaborate with community partners to develop their own recovery support groups to create a non-judgmental, compassionate, and stigma-free environment that promotes well-being and recovery.

\section{Increasing the Representation of Racial and Ethnic Minorities in Drug Court}

Since 2013, the drug court has experienced a significant decrease of racial and ethnic minority (non-White) participants in the program. Based on the demographics of St. Joseph County (Indiana), the primary populations that seem to not be equally represented in the drug court are African Americans, followed by Hispanics. In 2013, 49\% of the participants were non-White. However, this number decreased to $35 \%$ in the 2016 program evaluation and $21 \%$ in this 2019 study. It is recommended that the drug court increase the number of non-White participants in the program. Doing so may improve outcomes for African Americans and other racial and ethnic minorities. For instance, in 2013, when nearly half of the drug court was non-White participants, there were no racial disparities in outcomes, meaning White and non-White participants had similar graduation and recidivism rates. However, in 2016 and in this study, non-White participants did not seem to be equally represented in drug court and they were more likely to recidivate than White participants.

It is important to note that understanding why racial disparities exist in some drug courts is a complex phenomenon that requires a comprehensive solution. At this point, the recommendation is to increase the number of non-White participants in drug court. To do that, there are two suggestions. First, drug court stakeholders should market the program to defense attorneys, particularly the attorneys who commonly represent non-White participants. This marketing may increase the number of referrals the drug court receives from non-White participants. Second, the drug court should review their eligibility criteria to determine whether any criterion may inadvertently exclude non-White participants. According to Gallagher (2019b), criteria that seem to commonly exclude some non-White participants are having prior felony convictions, suspected gang involvement, ability to pay program fees (e.g. treatment, drug tests), perceived level of motivation for change, or perhaps denying someone drug court because they had previously participated in the program.

\section{Disseminating Drug Court Knowledge to the Community}

An essential component of CER is to disseminate the knowledge gained from studies to the community. From an academic standpoint, the norm in disseminating research findings is to publish articles in peer-reviewed journals and do presentations at national conference. These methods, however, are not practical in educating communities. The knowledge gained from the CER of the St. Joseph County (Indiana) drug court was successfully shared with the community in three ways. First, the researcher for the drug court facilitated multiple professional trainings and free public presentations to educate a range of people the role of drug court in their community. Additionally, a local 
university organized a community forum on the opioid epidemic and four drug court stakeholders were invited to be part of the panel presentation, including the drug court judge, researcher, social worker, and prosecutor. This was an opportunity to highlight how drug courts can be an effective approach in addressing the opioid epidemic.

Second, graduate students who were specializing in addiction and mental health treatment completed internships at drug court to assist with the CER and to provide them with an opportunity to observe drug court programming. Also, some undergraduate and graduate social work students completed service-learning projects in drug court, such as having students observe a traditional court hearing and drug court session and compare and contrast the experiences (Gallagher, 2015). These types of education (e.g. internships, service-learning) are important because students will graduate and practice in our communities, and they will now be able to share their knowledge on drug courts with others.

Third, the local news has supported drug court. ABC 57 news in South Bend, IN aired a story on how St. Joseph County (Indiana) has been a model in addressing the opioid epidemic, and one intervention discussed in the story was how the drug court was successfully using MAT to help those who have opioid use disorders (ABC 57 News, 2019). Additionally, WSBT news in Mishawka, IN aired a similar story where the drug court judge and researcher discussed how the drug court used science and evidence-based interventions, such as MAT, to support participants in their process of healing and recovery (WSBT News, 2019). Recently, the researcher for the drug court was interviewed by the inSocialWork podcast series where he completed a two-part podcast. In the first podcast, he discussed key components of the drug court model and highlighted research demonstrating their effectiveness (Gallagher, 2019c). In the second podcast, he shared his research findings related to the factors that may contribute to racial disparities in drug court graduation rates and articulated best practices in working with African American drug court participants (Gallagher, 2020). Local news stories and podcasts are, perhaps, the most efficient and effective method in disseminating knowledge to comminuties in an easily accessible and clear manner, without professional jargon. Plus, the information can be accessed on television, websites, and social media, which surely increases the number of community members who are learning about drug court.

\section{Limitations and Suggestions for Future Research}

This CER has several limitations, and it is recommended that future research address these limitations to continue adding to the knowledge base on the role of drug courts in communities. In this study, recidivism was only measured in St. Joseph County (Indiana). Therefore, if an individual recidivated in another county or state, that information was not captured. When available, recidivism data should be tracked statewide or even nationally, if possible. Next, the probation group was matched to the drug court group by two criteria, arrest/offense type and IRAS score. Probationers had an arrest/offense that was eligible for drug court but they did probation instead and both groups had a starting IRAS score of 21. These two criteria are important in matching the two groups, especially IRAS scores because criminogenic risk factors are consistently predictors of criminal justice outcomes (e.g. recidivism). Future research should enhance the matching process by also matching key demographics, such as gender, ethnicity, age, and criminal history (Brown, 2011). Last, to further promote community engagement, future research should use qualitative methods to explore community members' thoughts and opinions on the role of drug court in their community. Focus groups, for example, would be an effective method to assess community perception and understanding of drug court, and those findings could be compared and contrasted with drug court participants' experiences in the program and stakeholders' views on drug courts impact on the community. 


\section{References}

ABC 57 News. (2019, February). New article outlines St. Joseph County as model for fighting opioid epidemic [News broadcast]. In Local News. South Bend, IN: ABC 57 News. Available to view at:https://abc57.com/ news/new-article-outlines-st-joseph-county-as-model-for-fighting-opioid-epidemic

Aos, S., Miller, M., \& Drake, E. (2006). Evidence-based public policy options to reduce future prison construction, criminal justice costs, and crime rates. Federal Sentencing Reporter, 19, 275-290.

Brown, R. T. (2010). Systematic review of the impact of adult drug-treatment courts. Translational Research, 155, 263-274.

Brown, R. (2011). Drug court effectiveness: A matched cohort study in the Dane County drug treatment court. Journal of Offender Rehabilitation, 50, 191-201.

Friedmann, P. D., Hoskinson, R., Jr., Gordon, M., Schwartz, R., Kinlock, T., Knight, K., ... Frisman, L. K. (2012). Medication-assisted treatment in criminal justice agencies affiliated with the Criminal Justice-Drug Abuse Treatment Studies (CJ-DATS): Availability, barriers, and intentions. Substance Abuse, 33, 9-18.

Gallagher, J. R. (2013). Program evaluation of the St. Joseph County (South Bend), Indiana drug court. South Bend, IN: Indiana University South Bend, School of Social Work.

Gallagher, J. R., Ivory, E., Carlton, J., \& Woodward Miller, J. (2014). The impact of an Indiana (United States) drug court on criminal recidivism. Advances in Social Work, 15, 507-521.

Gallagher, J. R. (2015). Promoting drug court education in schools of social work: Ideas in action. Social Work Education: The International Journal, 34, 428-436.
Gallagher, J. R., Wahler, E. A., \& Lefebvre, E. R. (2016). Program evaluation of the St. Joseph County (Indiana) drug court. South Bend, IN: Indiana University South Bend, School of Social Work.

Gallagher, J. R., Wahler, E. A., Lefebvre, E., Paiano, T., Carlton, J., \& Woodward Miller, J. (2018). Improving graduation rates in drug court through employment and schooling opportunities and medication-assisted treatment (MAT). Journal of Social Service Research, 44, 343-349.

Gallagher, J. R., Marlowe, D. B., \& Minasian, R. M. (2019a). Participant perspectives on medication-assisted treatment for opioid use disorders in drug court. Journal for Advancing Justice, 2 , 39-54.

Gallagher, J. R. (2019b). Issue brief: Racial and ethnic disparities (RED) in treatment courts. Washington, DC: American University, Justice Programs Office, School of Public Affairs.

Gallagher, J. R. (2019c, December). Episode 276 - Dr. John Gallagher: It's all about relationships: Drug courts - what are they and how do they work? (part 1 of 2) [Audio podcast]. In inSocialWork Podcast Series. Buffalo, NY: University at Buffalo School of Social Work. Available to view at: https:// www.insocialwork.org/episode. asp?ep $=276$

Gallagher, J. R. (2020, January). Episode 278 - Dr. John Gallagher: It's all about relationships: Drug courts - what are they and how do they work? (part 2 of 2) [Audio podcast]. In inSocialWork Podcast Series. Buffalo, NY: University at Buffalo School of Social Work. Available to view at: https:// www.insocialwork.org/episode. asp?ep $=278$

Goldkamp, J. S. (1994). Miami's treatment drug court for felony defendants: Some implications of assessment findings. The Prison Journal, 74, 110-166.
Lowenkamp, C. T., Holsinger, A. M., \& Latessa, E. J. (2005). Are drug courts effective? A meta-analytic review. Journal of Community Corrections, 15, 5-28.

Marlowe, D. B., Hardin, C. D., \& Fox, C. L. (2016, June). Painting the current picture: Anational report on drug courts and other problem-solving courts in the United States. Alexandria, VA: National Drug Court Institute.

Matusow, H., Dickman, S. L., Rich, J. D., Fong, C., Dumont, D. M., Hardin, C., ... Rosenblum, A. (2013). Medication assisted treatment in US drug courts: Results from a nationwide survey of availability, barriers and attitudes. Journal of Substance Abuse Treatment, 44, 473-480.

Miethe, T. D., Lu, H., \& Reese, E. (2000). Reintegrative shaming and recidivism risks in drug court: Explanations for some unexpected findings. Crime \& Delinquency, $46,522-541$.

Mitchell, O., Wilson, D. B., Eggers, A., \& MacKenzie, D. L. (2012). Assessing the effectiveness of drug courts on recidivism: A meta-analytic review of traditional and non-traditional drug courts. Journal of Criminal Justice, 40, 60-71.

Narcotics Anonymous World Services, Inc. (2016). Narcotics Anonymous and persons receiving medication-assisted treatment. Chatsworth, CA: Author.

National Association of Drug Court Professionals. (2019). Justice for all. Retrieved from https:// www.nadcp.org

National Institute on Drug Abuse. (2016). Effective treatments for opioid addiction. Rockville, MD: Author.

Nolan, J. L. (2001). Reinventing justice: The American drug court movement. Princeton, NJ: Princeton University Press.
Schneider, R. D., Bloom, H., \& Hereema, M. (2007). Mental health courts: Decriminalizing the mentally ill. Toronto, Canada: Irwin Law.

Shaffer, D. K. (2011). Looking inside the black box of drug courts: A meta-analytic review. Justice Quarterly, 28, 493-521.

Slinger, E., \& Roesch, R. (2010). Problem-solving courts in Canada: A review and a call for empirically-based evaluation methods. International Journal of Law and Psychiatry, 33, 258-264.

U.S. Government Accountability Office. (2005). Adult drug courts: Evidence indicates recidivism reductions and mixed results for other outcomes (No. GAO-05219). Washington, DC: Author.

Wexler, D. B., \& Winick, B. J. (1996). Law in a therapeutic key: Developments in therapeutic jurisprudence. Durham, NC: Carolina Academic Press.

Wilson, D. B., Mitchell, O., \& MacKenzie, D. L. (2006). A systematic review of drug court effects on recidivism. Journal of Experimental Criminology, 2, 459-487.

WSBT News. (2019, February). Work in St. Joseph County to fight opioid epidemic getting international coverage [News broadcast]. In Local News. Mishawaka, IN: WSBT News. Available to view at: https://wsbt.com/news/ local/work-in-st-joseph-county-to-fight-opioid-epidemic-getting-international-coverage 